\title{
Investigation of the functional network modifier loading on the stoichiometric ratio of epoxy resins and their dielectric properties
}

\author{
Istebreq A. Saeedi ${ }^{1}$ (D), Sunny Chaudhary ${ }^{1, *}$ (D), Thomas Andritsch ${ }^{1}$ (D), and Alun S. Vaughan ${ }^{1}$ (]) \\ ${ }^{1}$ Department of Electronics and Computer Science, Tony Davies High Voltage Laboratory, Highfield Campus, University of \\ Southampton, University Road, Southampton SO17 1BJ, Hampshire, UK
}

Received: 21 December 2020

Accepted: 20 April 2021

Published online:

4 May 2021

(C) The Author(s) 2021

\begin{abstract}
Reactive molecular additives have often been employed to tailor the mechanical properties of epoxy resins. In addition, several studies have reported improved electrical properties in such systems, where the network architecture and included function groups have been modified through the use of so-called functional network modifier (FNM) molecules. The study reported here set out to investigate the effect of a glycidyl polyhedral oligomeric silsesquioxane (GPOSS) FNM on the cross-linking reactions, glass transition, breakdown strength and dielectric properties of an amine-cured epoxy resin system. Since many previous studies have considered POSS to act as an inorganic filler, a key aim was to consider the impact of GPOSS addition on the stoichiometry of curing. Fourier transform infrared spectroscopy revealed significant changes in the cross-linking reactions that occur if appropriate stoichiometric compensation is not made for the additional epoxide groups present on the GPOSS. These changes, in concert with the direct effect of the GPOSS itself, influence the glass transition temperature, dielectric breakdown behaviour and dielectric response of the system. Specifically, the work shows that the inclusion of GPOSS can result in beneficial changes in electrical properties, but that these gains are easily lost if consequential changes in the matrix polymer are not appropriately counteracted. Nevertheless, if the system is appropriately optimized, materials with pronounced improvements in technologically important characteristics can be designed.
\end{abstract}

Handling Editor: Gregory Rutledge.

Address correspondence to E-mail: sc6u16@ecs.soton.ac.uk

E-mail Addresses: i.a.h.saeedi@soton.ac.uk; t.andritsch@soton.ac.uk; asv@soton.ac.uk 


\section{Introduction}

It is generally accepted that the properties of a thermosetting resin system are strongly influenced by the structure of the constituent amorphous network and, consequently, a considerable body of work has been conducted to gain a better understanding of relationships between network topology and bulk macroscopic properties [1-3]. In order to modify the properties of an epoxy resin system, different approaches have been used, including the use of fillers with different sizes and shapes, controlling the chemical structure of the constituent components (resin, hardener and additives), varying the stoichiometric ratio, changing the curing regime, etc.

Although many studies have investigated the effect of altering the structure of epoxy resin systems through the addition of reactive moieties (so-called reactive diluents), the vast majority of such studies has focused on the mechanical properties of the modified material [4-6]. However, a small number of studies reported in the literature have considered the impact of comparable species on electrical properties [7], where the concept was based on covalently bonding functional groups into the network. This strategy was termed functional network modification (FNM). However, few of these studies have considered in detail the effect of the modifier on the curing reaction and stoichiometry of the system. Changing the stoichiometric epoxy:hardener ratio is reported to affect the thermal [8], mechanical $[9,10]$ and electrical $[11,12]$ properties of epoxy resin systems.

For epoxy resin-based systems, maintaining an appropriate reactant stoichiometry is a crucial aspect, as it is one of the principal factors influencing the degree of cross-linking. The presence of functional groups in the bulk system can also have a significant effect on the ultimate electric properties. Indeed, an investigation by Nguyen et al. [12] of epoxy resins demonstrated the marked reduction in dielectric breakdown strength that occurs when systems are formulated using an unbalanced stoichiometry. Separate work has demonstrated that the presence of unreacted amines can markedly increase electrical conductivity [13]. Although such results cannot demonstrate unambiguously that residual functional groups degrade the electrical properties of cured epoxy resins, they do highlight stoichiometry as a relevant and contributory factor. Conversely, the inclusion of tailored functional groups through the addition of an appropriate FNM has the potential to influence the curing reaction and, since stoichiometry plays an important role in determining the final cross-linked structure, such factors must be carefully evaluated in order to account for changes in reactive components.

In the study reported here, we set out to explore the effect of a glycidyl polyhedral oligomeric silsesquioxane (GPOSS) FNM on the electrical characteristics of an epoxy resin and, in particular, to examine the impact on bulk properties of any consequent changes in stoichiometry. This was achieved by comparing two different sets of samples and evaluating their performance as dielectric materials based on their bulk electrical properties. Specifically, two sample sets were considered. In the first of these, the included POSS was considered as a molecular reactant and the reaction stoichiometry was compensated accordingly, such that the ratio of epoxide group and amine group was held constant, taking into account the additional epoxide groups supplied by the GPOSS. In the second, uncompensated set of systems, the POSS was simply considered as a silicabased nanofiller, whereby the matrix resin formulation was held constant throughout and the GPOSS was simply added to give the required weight percentage. Such uncompensated system should therefore contain an excess of epoxide groups and a different network structure compared to compensated equivalents. Knowing this, the influence of residual functional groups and their impact on the molecular dynamics can be explored, analysed and the disparity between both system types can be established through dielectric processes.

\section{Experiment}

\section{Materials and sample preparation}

The samples examined in this study were formulated using the following three components. The epoxy resin was a diglycidyl ether of bisphenol A (DGEBA) epoxy resin (DER 332, $n \approx 0.028$ - molar mass $340 \mathrm{~g} \mathrm{~mol}^{-1}$ ) supplied by Sigma Aldrich, which has an epoxide equivalent weight (EEW) of 172-176 $\mathrm{g} \mathrm{mol}^{-1}$. The chosen FNM was a glycidyl polyhedral oligomeric silsesquioxane (GPOSS molar mass $1338 \mathrm{~g} \mathrm{~mol}^{-1}$ ) supplied by Hybrid- 
Plastics (EP0409) with an EEW of $167.23 \mathrm{~g} \mathrm{~mol}^{-1}$. Finally, the chosen hardener was the commercial polyetheramine system Jeffamine D-230 (molar mass about $230 \mathrm{~g} \mathrm{~mol}^{-1}$ ), with an amine hydrogen equivalent weight of $60 \mathrm{~g} \mathrm{~mol}^{-1}$. The chemical structure of each of these compounds is shown in Fig. 1. To produce the samples, the epoxy resin was first preheated at $50{ }^{\circ} \mathrm{C}$ for $60 \mathrm{~min}$ to reduce its viscosity, after which time, the required masses of resin, FNM and hardener were thoroughly mixed using a magnetic stirrer, for $10 \mathrm{~min}$. The resultant mixture was then degassed and cast into steel mould, which were then placed in a fan oven. The curing regime was selected based on a previous study [14], where the samples were cured at $80{ }^{\circ} \mathrm{C}$ for $120 \mathrm{~min}$, then postcured at $125{ }^{\circ} \mathrm{C}$ for $180 \mathrm{~min}$ to give uniform film specimens with a nominal thickness of $200 \mu \mathrm{m}$. These were stored in vacuum until use.

Two approaches were used in formulating the systems containing GPOSS. First, the GPOSS was added by carefully evaluating the stoichiometric ratios through calculating the overall epoxide content of the system (DER 332 plus GPOSS). Then, the required quantity of Jeffamine D-230 was added, such that the total number of epoxide groups in the system equal to the number of amine hydrogens accounting for both $\mathrm{N}-\mathrm{H}$ protons. Samples were manufactured with different loadings of epoxide groups supplied by the GPOSS (1 EG\%, 4 EG\%, 10 EG\% and 30 EG\%). Subsequently, such specimens are referred to as epoxide compensated systems and designated X EG\% GPOSS, where $X$ indicates the number percentage of epoxide groups supplied by the GPOSS. This approach equates to treating the GPOSS explicitly as a molecular reactant. Second, the FNM was added as a simple weight percentage of the combined mass of DER 332 and Jeffamine D-230 ( $1 \mathrm{wt} \%, 4 \mathrm{wt} \%, 10 \mathrm{wt} \%$ and $30 \mathrm{wt} \%$ ), without modifying the ratio of DER 332 to Jeffamine D-230. Subsequently, such specimens are referred to as epoxide uncompensated systems and are designated $\mathrm{Y}$ wt $\%$ GPOSS, where $Y$ indicates the weight per cent of the GPOSS. This approach equates to treating the GPOSS as a silica-based nanofiller, as in a number of previous studies $[15,16]$. The formulation of each system is listed in Table 1.

\section{Characterization techniques}

Samples produced as above were characterized using the following techniques. An attenuated total internal reflectance (ATR) Fourier transform infrared (FTIR) spectrometer system (ATR-FTIR iD7 Nicolet iS5 from ThermoScientific) was used to obtain FTIR spectra. Before spectra were obtained from any of the above<smiles>COc1ccc(C(C)(C)c2ccc(OCC(O)COc3ccc(C(C)(C)c4ccc(OCC5CO5)cc4)cc3)cc2)cc1</smiles>

(b)

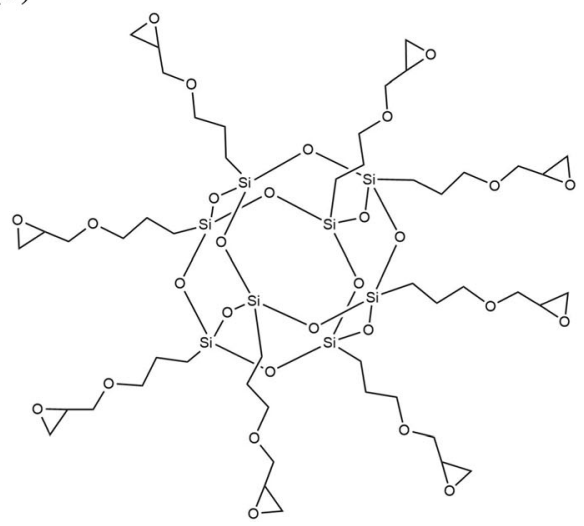

(c)<smiles>[Y]C(C)(CC(C)N)OCC(C)C(C)(C)N</smiles>

Figure 1 The chemical structure of a resin (DER 332), b functional network modifier (GPOSS) and $\mathbf{c}$ the hardener (Jeffamine). 
Table 1 Formulation of the reference and GPOSS modified systems

\begin{tabular}{lllll}
\hline Material system & Resin $(\mathrm{g})$ & FNM $(\mathrm{g})$ & Hardener $(\mathrm{g})$ & FNM wt $\%$ \\
\hline Neat Epoxy & 7.45 & 0.00 & 2.55 & 0 \\
$1 \mathrm{EG} \%$ & 7.38 & 0.07 & 2.55 & 0.7 \\
$4 \mathrm{EG} \%$ & 7.15 & 0.29 & 2.56 & 2.9 \\
$10 \mathrm{EG} \%$ & 6.73 & 0.71 & 2.56 & 7.6 \\
$30 \mathrm{EG} \%$ & 5.26 & 2.16 & 2.58 & 27.6 \\
$1 \mathrm{wt} \%$ & 7.45 & 0.10 & 2.55 & 1 \\
$4 \mathrm{wt} \%$ & 7.45 & 0.40 & 2.55 & 4 \\
$10 \mathrm{wt} \%$ & 7.45 & 1.00 & 2.55 & 10 \\
$30 \mathrm{wt} \%$ & 7.45 & 3.00 & 2.55 & 30
\end{tabular}

specimens, a background check was run and, then, data were acquired from 4000 to $500 \mathrm{~cm}^{-1}$. Each spectrum was an average of 16 measurements, OMNIC software was used to collect the spectra and, subsequently, these were standardized using a standard normal variate correction approach.

For each system, the glass transition temperature $\left(T_{g}\right)$ was determined by differential scanning calorimetry (DSC). For this, a Perkin Elmer DSC7 was used, after being calibrated using $5 \mathrm{mg}$ of high purity indium. Data were acquired under a nitrogen atmosphere and all samples were subjected to two thermal cycles using a heating/cooling rate of $10{ }^{\circ} \mathrm{C} \mathrm{min}{ }^{-1}$. First, the specimen was heated from 20 to $170{ }^{\circ} \mathrm{C}$, then cooled from 170 to $20^{\circ} \mathrm{C}$ and, finally, heated again from 20 to $170{ }^{\circ} \mathrm{C}$. All the data reported here were obtained from the second heating scan.

The dielectric response of the samples was measured using a Solartron 1296 dielectric interface linked to a Schlumberger SI 1260 impedance gainphase analyser, which was connected to a sample holder incorporating parallel $30 \mathrm{~mm}$ circular electrodes. To ensure good contact between the sample and the electrodes, the opposing surfaces of each sample were sputtered with circular gold electrodes, $30 \mathrm{~mm}$ in diameter. Dielectric measurements were conducted at room temperature and the data were acquired as a function of frequency from $0.1 \mathrm{~Hz}$ to $0.1 \mathrm{MHz}$ using an applied AC voltage of amplitude $1 \mathrm{~V}$.

The AC breakdown behaviour of the various systems was examined using a Phoenix Type 600C instrument. A ramped $50 \mathrm{~Hz}$ AC voltage was applied to the sample of interest and increased at a rate of $500 \mathrm{~V} / \mathrm{s}$ until failure occurred. The test cell comprised of two opposing steel ball-bearing electrodes, of diameter $6.3 \mathrm{~mm}$, which were replaced every 10 tests, to prevent electrode pitting from potentially affecting the acquired breakdown data. Each sample was placed between the ball bearings and immersed in silicone oil to present flashover, 15 to 20 sites were tested for each system and the resulting data were analysed assuming a two parameters Weibull distribution function, as is common practice.

\section{Results and discussion}

\section{FTIR spectroscopy}

Figure 2 provides an overview of the FTIR spectra obtained from all the systems considered here, spanning the complete sampled range; as indicated above, these data were processed using a standard normal variate approach. While this is sufficient for many purposes, to permit a more quantitative comparison of sample-to-sample variations, the data were further processed using the absorption at $1509 \mathrm{~cm}^{-1}$ as an internal calibrant. This feature is commonly ascribed to phenyl carbons [17] and, since the DER 332 content of all the systems considered here is known, the strength of the absorption at this wavenumber provides a means of scaling each spectrum. Such an approach has previously been employed elsewhere [18-20]. The resulting data will henceforth be referred to as scaled data/spectra and, in discussing these, three spectral regions are of particular interest, namely, around $3400 \mathrm{~cm}^{-1}$, from 1250 to $1080 \mathrm{~cm}^{-1}$ and from 970 to $915 \mathrm{~cm}^{-1}$.

Consider, first, absorption around $3400 \mathrm{~cm}^{-1}$, which is associated with hydroxyl groups [21-23] (see Fig. 3). During the curing process, epoxide groups in the system react with primary/secondary amines supplied by the hardener, to generate a hydroxyl group and a secondary/tertiary amine. Both the resin and the GPOSS contain epoxide groups 

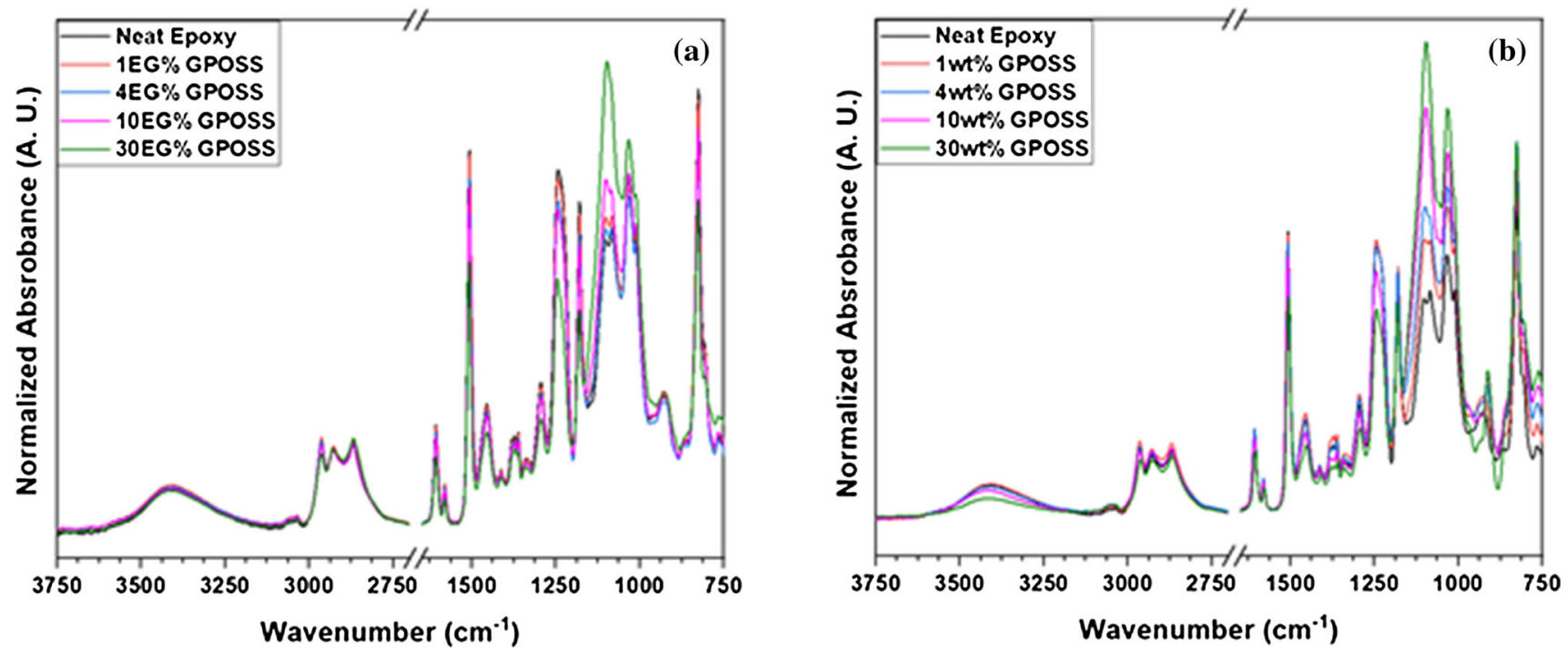

Figure 2 FTIR spectra of reference and GPOSS modified systems: a compensated stoichiometry; $\mathbf{b}$ uncompensated stoichiometry.
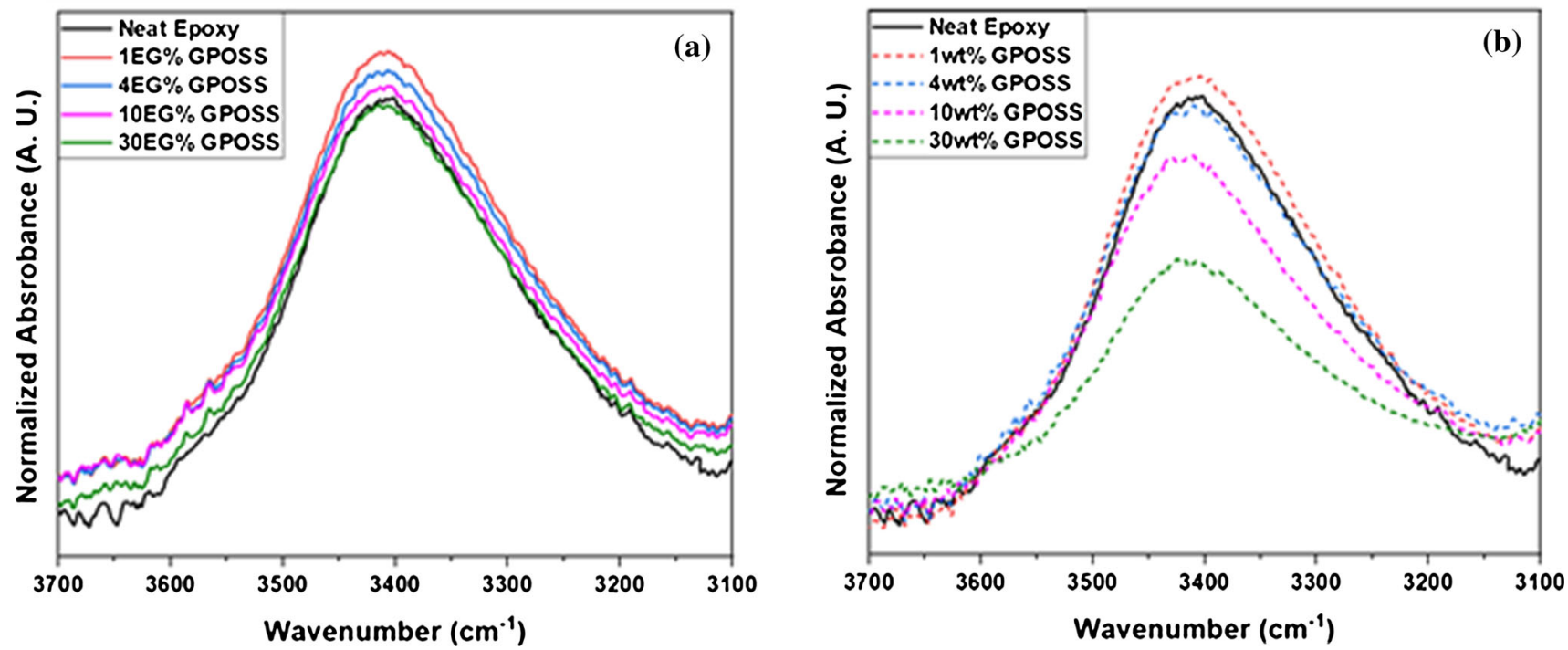

Figure 3 FTIR spectra of reference and GPOSS modified systems illustrating hydroxyl peaks observed at $\sim 3400 \mathrm{~cm}^{-1}$ : a compensated system, showing little variance in intensity; $\mathbf{b}$ uncompensated systems having significantly varying intensity.

within their chemical structure and, therefore, variations in the stoichiometric ratio of the resin/GPOSS/ hardener would be expected to impact the FTIR spectra of the systems in this region. In the case of the compensated systems (X EG\% GPOSS), the substitution of epoxide groups from the resin with epoxide groups from the GPOSS results in only small variations in the hydroxyl region of the spectra (see Fig. 3a) and, where differences do exist, these are mainly related to small baseline offsets. Conversely, in the case of the uncompensated systems, absorption related to $\mathrm{OH}$ groups decreases progressively as the
GPOSS loading increases, as shown in Fig. 3b. Comparing the reference epoxy with the $30 \mathrm{wt} \%$ GPOSS system, for example, the integrated intensity under the hydroxyl peak is reduced by more than $30 \%$ in the latter system; in contrast, the specific amount of hardener used to formulate $30 \mathrm{wt} \%$ GPOSS is reduced by less than $25 \%$ compared with the reference system based upon a balanced epoxide/amine stoichiometry. As such, while the reduction in the $\mathrm{OH}$ content is likely to be, predominantly, a consequence of reduced cross-linking reactions between epoxide groups and the hardener in the 
uncompensated systems, the magnitude in this appears to be somewhat in excess of expectations based solely in stoichiometric variations, implying that additional factors are also influencing the data.

Figure 4 shows a spectral region chosen to include the range from 1250 to $1080 \mathrm{~cm}^{-1}$, which is related strongly to ether groups; these can be divided into aromatic, aliphatic and disilyl categories. The pronounced peak spanning $1250-1230 \mathrm{~cm}^{-1}$ has previously been ascribed to the antisymmetric stretching of phenyl ethers [24, 25] and, as such, its intensity should be determined solely by the DER 332 content of each system. As indicated above, absorption at

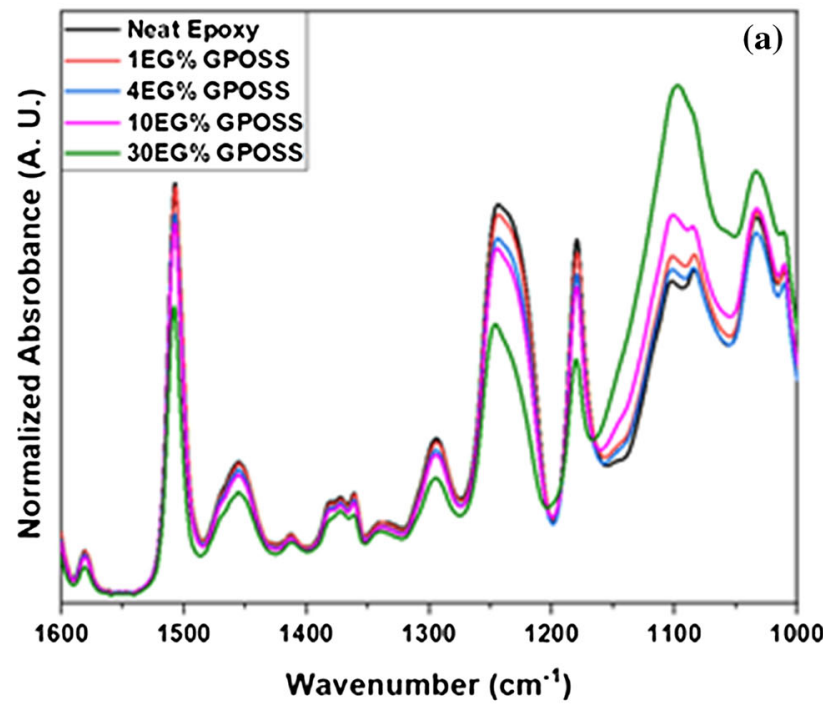

$1509 \mathrm{~cm}^{-1}$ relates to the same molecular component and, therefore, the strength of these two peaks should be linearly related, as is the case. Absorption in the range $1180-1140 \mathrm{~cm}^{-1}$ has previously been ascribed to organic ethers, including both aliphatic and aromatic $[26,27]$. As such, the strength of this absorption band should be determined by the cumulative effect of the aromatic ether groups in the DER 332, the aliphatic ethers within the POSS structure plus any ethers formed during curing. Absorbance at $1040 \mathrm{~cm}^{-1}$ has, similarly, been associated with the stretching of both (a) aromatic ethers [28] and (b) aliphatic ethers [24].

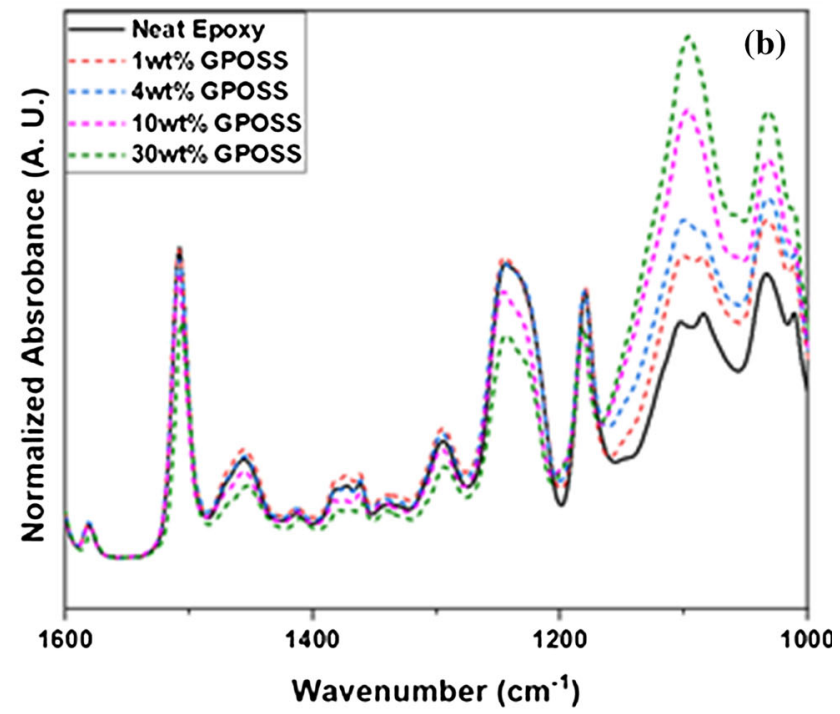

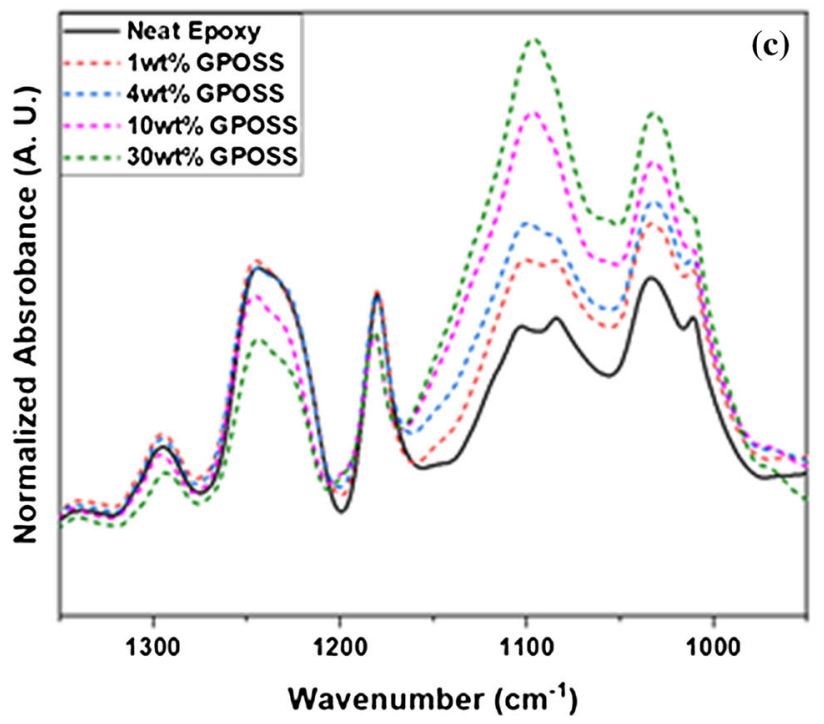

Figure 4 FTIR spectra of reference and GPOSS modified systems for a compensated systems in $1600-1000 \mathrm{~cm}^{-1}$ absorbance range b uncompensated systems in the $1600-1000 \mathrm{~cm}^{-1}$ absorbance range $\mathrm{c}$ uncompensated systems in comparsion with reference neat epoxy in the $1350-950 \mathrm{~cm}^{-1}$ absorbance range. 
Consider, first the series of compensated systems (X EG\% GPOSS), where the epoxide/amine ratio was held constant (see Fig. 4a). Since DER 332 is very close in composition to the ideal DGEBA case, for every epoxide group there will be very close to one aromatic ether; the GPOSS structure, similarly, contains one aliphatic ether per epoxide group. Consequently, while the substitution of DER 332 epoxides with GPOSS epoxides will have some effect on the specific total ether content of the compensated systems, due to their different EEW values, this factor will, in practice, be negligible. The marked reduction in the intensity of the absorption around $1160 \mathrm{~cm}^{-1}$ is therefore not consistent with the assertion that absorption in the range $1180-1140 \mathrm{~cm}^{-1}$ is simply the cumulative effect of all organic ethers, including both aliphatic and aromatic [26, 27]. Rather, the intensity of the absorption around $1160 \mathrm{~cm}^{-1}$ varies in a comparable manner to that discussed above for the $1250-1230 \mathrm{~cm}^{-1}$ region, suggesting therefore, that absorption around $1160 \mathrm{~cm}^{-1}$ is primarily of a similar origin - aromatic ether groups. Considering, now, the absorption at $1040 \mathrm{~cm}^{-1}$, where two features are worthy of note: the reference epoxy system, which should contain no aliphatic ethers, is characterized by appreciable absorption around this wavenumber; substitution of DER 332 epoxide groups with the same number of GPOSS epoxide groups results in a marked increase in the strength of the absorption at the wavenumber. While overlap with the strong and broad disilyl ether peak around $1080 \mathrm{~cm}^{-1}$ that is associated with the silica core of the GPOSS complicates matters somewhat, as discussed elsewhere, we nevertheless, suggest that these data corroborate previous publications that have associated this absorption band with both aromatic and aliphatic ethers but suggest that the influence of the latter may be dominant [29].

In the case of the uncompensated systems ( $\mathrm{Y}$ wt\% GPOSS), significant differences in behaviour are evident (see Fig. $4 \mathrm{~b}$ and c). First, while the $10 \mathrm{wt} \%$ GPOSS and $30 \mathrm{wt} \%$ GPOSS systems both clearly evince reduced absorbance at $1160 \mathrm{~cm}^{-1}$, this is not so apparent for the systems containing $1 \mathrm{wt} \%$ and $4 \mathrm{wt} \%$ of GPOSS, presumably, due to peak overlaps that, effectively, serve to increase the background absorption. Nevertheless, in general, the effect of GPOSS introduction on the absorption around $1160 \mathrm{~cm}^{-1}$ appears equivalent in both the compensated and uncompensated sample sets - a reduced fraction of DER 332 leads to reduced absorption, as would be expected if this absorption band, as proposed, were primarily related to the aromatic ether content of the system. Conversely, the absorbance at $1040 \mathrm{~cm}^{-1}$ appears to increase more dramatically on the inclusion of GPOSS in the $\mathrm{Y}$ wt $\%$ GPOSS systems, compared with the equivalent, compensated X EG\% GPOSS samples set (see Fig. 4c, which compares selected data). While a contributory factor to this is that, for any case where $X=Y, Y$ wt $\%$ GPOSS systems contains somewhat more GPOSS per unit mass of sample than does the nominally equivalent X EG\% GPOSS (see Table 1), this difference is not great ( $\sim 10 \%$ when $\mathrm{X}=\mathrm{Y}=30$ ). Therefore, this factor is insufficient to account for the marked differences shown. While epoxide/amine reactions dominate under the curing conditions used here, where an excess of epoxide groups is present, it has been shown that etherification/homopolymerization reactions between epoxide and hydroxyl group can occur and that this increases in importance with increasing temperature. We therefore suggest that the increased absorbance seen at $1040 \mathrm{~cm}^{-1}$ in, for example, $30 \mathrm{wt} \%$ GPOSS compared with 30 EG\% GPOSS, is due to the reaction of excess epoxide and hydroxyl groups in the former system, leading to the formation of additional aliphatic ethers. Since etherification/ homopolymerization involves consumption of hydroxyl groups, this suggestion also explains the hydroxyl deficit discussed above in connection with Fig. 3b.

Figure 5 shows the FTIR spectral range associated with epoxide groups. From Fig. 5a, all systems formulated with a compensated stoichiometry exhibit comparable absorption within the wavelength region shown; the peak shape varies little from system to system, as does the peak intensity. Conversely, in the systems where the inclusion of GPOSS was not stoichiometrically compensated, systematic variations are evident. Contrast, for example, data obtained from the reference epoxy with those from the $30 \mathrm{wt} \%$ GPOSS system. The absorption peak in the latter system is characterized by a pronounced peak spanning the wavenumber range $900-920 \mathrm{~cm}^{-1}$, together with a broad shoulder at higher wavenumbers; in the reference epoxy, the absorption takes the form of a single broad feature (peak maximum $\sim 930 \mathrm{~cm}^{-1}$ ) which, presumably, equates to the high wavenumber shoulder seen in the spectrum of the $30 \mathrm{wt} \%$ GPOSS 


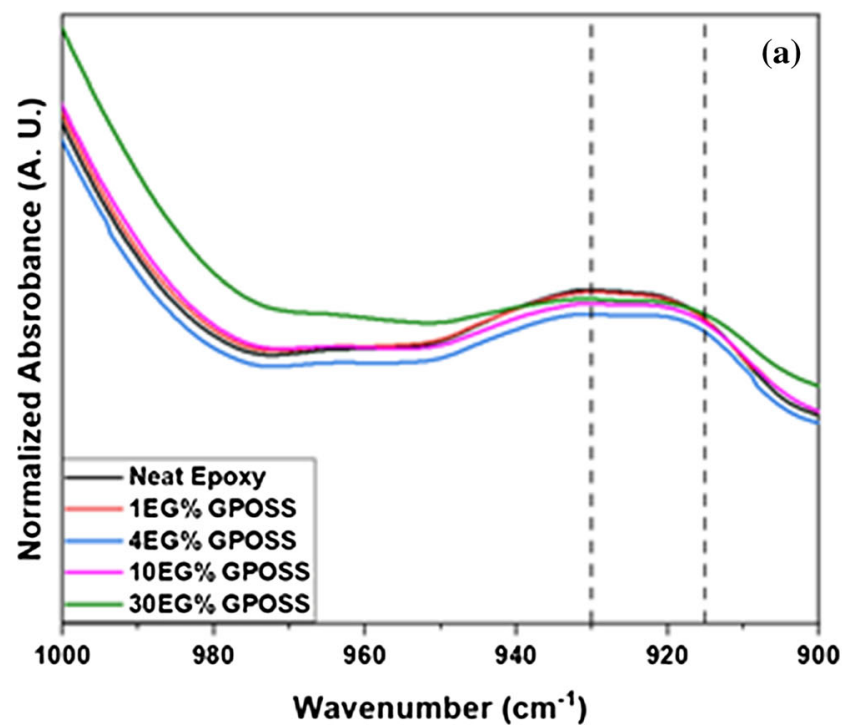

Figure 5 FTIR spectra of reference and GPOSS modified systems illustrating the epoxide absorbance region $1000-870 \mathrm{~cm}^{-1}$ for a compensated systems $\mathbf{b}$ uncompensated systems in comparison

system. Intermediate formulations are characterized by a progressive variation between these extremes.

The spectral region shown in Fig. 5 has been widely used as a means of evaluating the consumption of epoxide groups through curing reactions. For example, Cholake et al. [18] contrasted the evaluation of the extent of cure of an amine/DGEBA system using a number of different absorption bands in both the near and mid-IR (mIR) spectral regions. This study concluded that, while the use of absorbance around $915 \mathrm{~cm}^{-1}$ is not straightforward during the final stages of curing, where the epoxy concentration is low and the accurate evaluation of the strength of the $915 \mathrm{~cm}^{-1}$ band is consequently challenging, this approach nevertheless "gives most accurate results in mIR region". The above conclusions were drawn using data published by Fraga et al. [30], which reveal reduced absorption at $915 \mathrm{~cm}^{-1}$ with increased curing time, plus evidence of a relative increase in absorption around $935 \mathrm{~cm}^{-1}$ as curing proceeds; equivalent behaviour has also been reported in an FTIR study of the curing behaviour of DGEBA/octaglycidyl-POSS systems [31]. While, in the above examples, C-O oxirane stretching was taken to result in absorption at $915 \mathrm{~cm}^{-1}$, this wavelength is not ubiquitous and, rather, is dependent upon the local environment. For example, the equivalent vibrational mode has been observed at $907 \mathrm{~cm}^{-1}$ in tetraglycidyl diamino diphenyl methane and, of particular

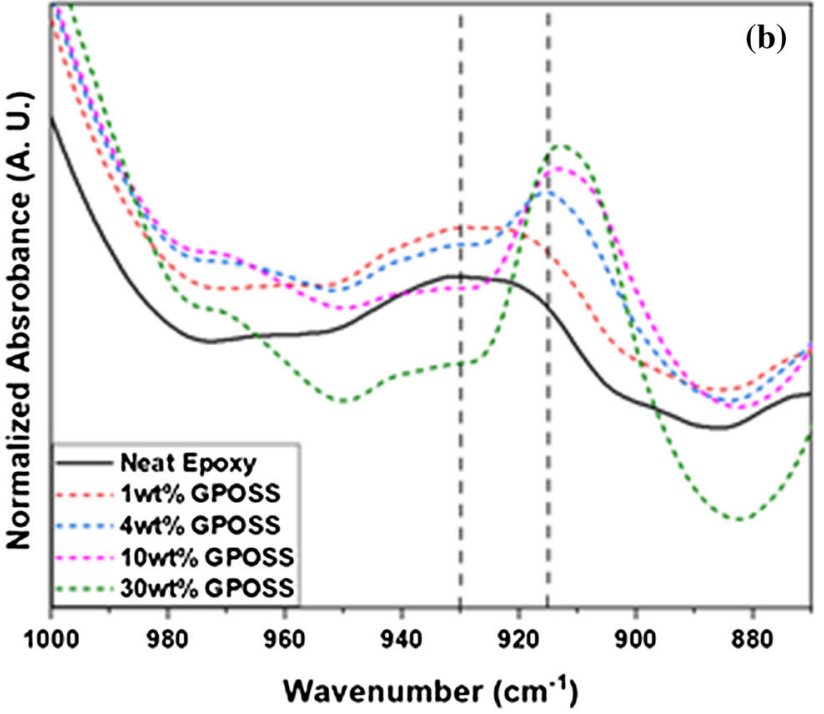

with where the dashed lines at $915 \mathrm{~cm}^{-1}$ represents the GPOSS's epoxide peak and at $930 \mathrm{~cm}^{-1}$ represents the epoxide peak originating from epoxy resin.

relevance to the work described in this publication, has been reported to be displaced to a wavenumber below $915 \mathrm{~cm}^{-1}$ in the same commercial octaglycidylPOSS used here [31]. As such, we interpret the data shown in Fig. 5 as follows.

The comparability of the FTIR absorption around $930 \mathrm{~cm}^{-1}$ (remnant epoxide-related peak) seen in the $X$ EG\% GPOSS systems aligns well with the invariance in the absorption around $3400 \mathrm{~cm}^{-1}$ (hydroxylrelated peak) discussed previously and suggests similar levels of cross-linking in all these systems. In contrast, in the $\mathrm{Y}$ wt\% GPOSS systems, the increasing excess epoxide content results in increased absorption around $915 \mathrm{~cm}^{-1}$ as a consequence of unreacted epoxide groups, whose FTIR behaviour mirrors that of the reactants. Furthermore, comparison of the data obtained from $4 \mathrm{wt} \%$ GPOSS and $30 \mathrm{wt} \%$ GPOSS reveals not just an increase in the strength of the absorption peak in the latter system but also its displacement to lower wavenumbers. As it has been reported that the $\mathrm{C}-\mathrm{O}$ oxirane stretching vibration occurs at a lower wavenumber in GPOSS than in DGEBA [31], this variation may indicate the preferential consumption of epoxide groups from the latter component.

From the above account, it can be seen that, in the case of the X EG\% GPOSS compensated systems, the addition of GPOSS results in only small variation in the acquired FTIR spectra, suggesting that 
substitution of epoxy groups from the DER 332 resin with epoxide groups from the GPOSS has only a minor effect on the reactions that occur within the system during curing. However, the variations seen in the range 1150 to $1000 \mathrm{~cm}^{-1}$ suggests that this equivalence is not exact, albeit that interpretation of the changes seen in the wavenumber range are complicated by the presence of the strong di-silyl ether absorption from the GPOSS core. In the case of the uncompensated $\mathrm{Y}$ wt\% GPOSS systems, the inclusion of the GPOSS resulted in reduced absorption in the hydroxyl region of the spectrum, which we associate with two factors: a reduction in hydroxyl formation through the reaction of epoxide and amine groups; consumption of hydroxyl groups by their reaction with excess epoxides, giving rise to the formation of additional aliphatic ethers. Furthermore, particularly at high GPOSS loading levels, the $\mathrm{Y}$ wt $\%$ GPOSS systems exhibit feature that we interpret as retained, unreacted epoxide groups present as chain ends within the system.

\section{Differential scanning calorimetry}

Heat flow data obtained by DSC are presented in Fig. 6, which show the influence of the material composition on the glass transition of GPOSS modified systems. Derived $T_{g}$ values, defined here as the inflection point of the DSC traces, for both compensated and uncompensated GPOSS-modified systems are listed in Table 2. From Table 2, it can be seen that the addition of GPOSS suppresses $T_{g}$ in both sets of system, albeit that the reduction in $T_{g}$ is much more marked in the uncompensated systems. As such, we suggest that while non-ideal stoichiometries serve to reduce $T_{g}$, so does the substitution of epoxide groups from the DER 332 with epoxide groups from GPOSS and that both affects act in an additive manner. These findings are in good agreement with the behaviour of the $T_{g}$ reported for epoxy resin systems modified by the inclusion of different POSS-based moieties, including (triglycidylisobutyl-POSS (TGIB-POSS) [32], octaepoxy-POSS [33] and octa(aminophenyl)silsesquioxane [34]. In the case of the compensated systems, the variation in $T_{g}$ resulting from the inclusion of the GPOSS may be associated with a number of factors.

Consider, first, changes in free volume, since a significant body of work has been reported concerning the relationship between $T_{g}$ and the free volume present within resin networks [35-38]. In the systems studied here, the reaction of the epoxide functional groups within the GPOSS structure results in the incorporation of the silica core as nodes within the thermoset resin network. The resulting network topology will, therefore, be altered, which may lead to the free volume present within the system being increased. The increase in the free volume can also result from a localized plasticization effect formed around the unreacted GPOSS groups, in a behaviour similar to the localized plasticizing effects observed on the addition of low molecular weight compounds suggested by $\mathrm{Su} \mathrm{C}-\mathrm{H}$ et al.[39]. However, Hao et al. [40] suggested that the presence of POSS molecules in POSS-rich polymeric networks results in a reduction in free volume; Raftopoulos et al. [41] concluded that

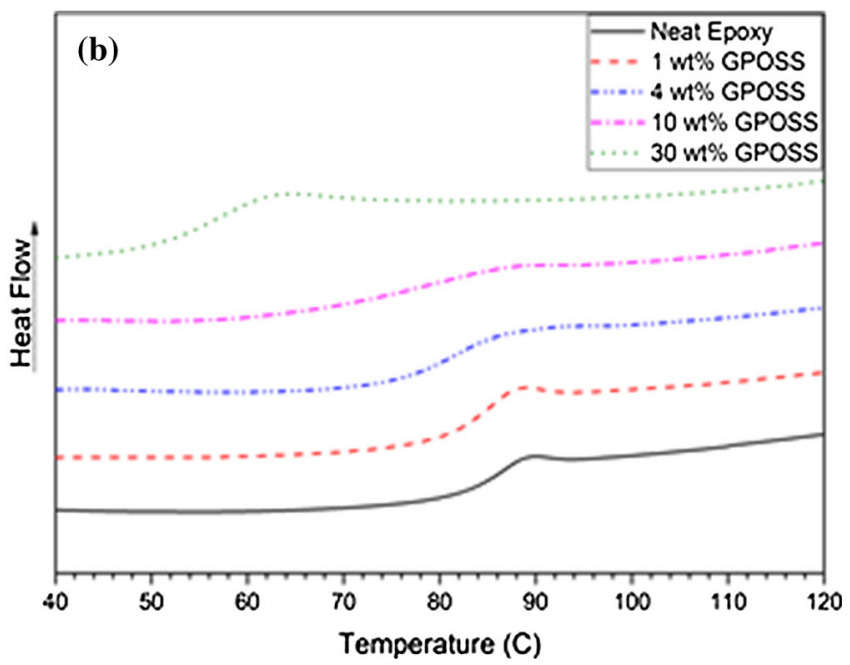

Figure 6 DSC traces of reference and GPOSS modified systems for a compensated systems $\mathbf{b}$ uncompensated systems. 
Table 2 DSC measurements for reference and GPOSS modified epoxy systems

\begin{tabular}{|c|c|c|c|c|}
\hline \multirow[t]{2}{*}{ Sample } & \multicolumn{2}{|c|}{ Compensated systems } & \multicolumn{2}{|c|}{ Uncompensated systems } \\
\hline & $T_{g}^{*}\left({ }^{\circ} \mathrm{C}\right)$ & Width of $\boldsymbol{T}_{g}\left({ }^{\circ} \mathrm{C}\right)$ & $\boldsymbol{T}_{g}{ }^{*}\left({ }^{\circ} \mathrm{C}\right)$ & Width of $\boldsymbol{T}_{g}\left({ }^{\circ} \mathrm{C}\right)$ \\
\hline Neat epoxy & 85.3 & 18 & 85.3 & 18 \\
\hline $1 \%$ & 84.9 & 19 & 83.2 & 21 \\
\hline $4 \%$ & 84.4 & 20 & 81.6 & 28 \\
\hline $10 \%$ & 80.1 & 22 & 78.1 & 41 \\
\hline $30 \%$ & 75.7 & 24 & 57.5 & 45 \\
\hline
\end{tabular}

*Uncertainty in $T_{g}: \pm 2{ }^{\circ} \mathrm{C}$
POSS molecules influence the $T_{g}$ of the host polymer by acting as immobile units within the system. Such assertions suggest that the reduction in $T_{g}$ reported here for the GPOSS modified systems should, therefore, be the consequence of factors other than increased free volume.

From Table 1, it is evident that systems 1 EG\% GPOSS to and 4 EG\% GPOSS exhibit $T_{g}$ values that are statistically equivalent to that of the reference systems, while higher loading levels lead to significant reductions in $T_{g}$. For low GPOSS loadings, Lee and Lichtenhan [42] reported increased $T_{g}$ values for such modified systems, which they associated with the presence of the cage-like structures of the POSS; Liu et al. [43] suggested that POSS can improve the thermal stability of the resin system by restricting chain mobility. Elsewhere, Heid et al. [44] reported that high loadings of GPOSS (about $20 \mathrm{wt} \%$ ) displaced $T_{g}$ to lower values (reduced by $7{ }^{\circ} \mathrm{C}$ ), a result they explained in terms of increased chain mobility resulting from reduced cross-linking density in the modified systems, where the inclusion of high loading of GPOSS was suggested to generate regions in which the POSS molecules interacted leading to their crystallization. It is worth highlighting that, although this work claimed stoichiometric compensation, the methodology used was not disclosed for "confidentiality reasons", preventing objective assessment of the approach. Similarly, Florea et al. [45] proposed that in systems formulated using sufficiently large numbers of POSS molecules, these would interact with each other forming localized regions containing a high concentration of POSS. Finally, Takala et al. [46] used epoxy-functionalized POSS molecules of a comparable form to that used in this study together with an anhydride-cured BADGE resin and, as in our work, reported a gradual reduction in $T_{g}$. Although this study did not clearly address stoichiometric factors, which can clearly suppress $T_{g}$, these workers highlighted the role of flexible vertex-bonded side chains present in both of their POSS systems as key elements that serve to increase molecular mobility. A similar explanation has been proposed in connection with the observed reduction in $T_{g}$ in DGEBA polymerized together with hydroxy-functionalized POSS in the presence of a tertiary amine catalyst [47]. A related contributory factor could be the reduction in the concentration of aromatic groups within the system that is an inevitable consequence of the substitution of DGEBA epoxy groups with GPOSS epoxy groups; according to Neville and Lee [48], aromatic groups influence the glass transition temperature of the epoxy resin, where systems with reduced aromatic contents are reported to have deteriorated thermal behaviour. Bacosca et al. [49] suggested that the glass transition temperature is related to the number of aromatic rings available in the system, while Ramirez et al. [33] explained that the presence of aromatic groups in the polymeric structure hinders the segmental rotation motion during the glass transition process, which would shift $T_{g}$ to higher temperatures. In summary, we suggest that the reduction in $T_{g}$ seen in the stoichiometrically compensated systems is best understood in terms of changes in network topology and associated molecular constraints.

In the case of the uncompensated systems, $T_{g}$ decreases more rapidly with increasing GPOSS concentration and the glass transition process is broadened significantly compared with the compensated systems described above. For instance, comparison of the behaviour of $30 \mathrm{EG} \%$ GPOSS and $30 \mathrm{wt} \%$ GPOSS reveals a dramatic increase in the width of glass transition, $\Delta T_{g}$, in the latter system, from 6 to $27^{\circ} \mathrm{C}$. In the uncompensated systems, the total number of epoxide groups from both the DER 332 and the GPOSS exceeds the number of reactive groups provided by the hardener. Under such circumstances, 
the curing reactions may proceed until, ideally, all active groups of the hardener are consumed. The FTIR data discussed above suggest that, although some etherification occurs, a significant fraction of unreacted epoxide groups remain within the network as chain ends. The reduced degree of overall crosslinking that results, combined with variations in the local network topology and free volume, explain the observed marked reduction in $T_{g}$ and the increase in $\Delta T_{g}$ seen in the $\mathrm{Y}$ wt $\%$ GPOSS systems. Furthermore, the width of the glass transition process indicates a variation in local constraints and/or that number of different molecular configurations/species contributing to the observed behaviour in the glass transition region [50]. To conclude, we suggest that the variations in $T_{g}$ shown in Fig. 6 are a result of two factors that act additively: the introduction of GPOSS serves directly to reduce $T_{g}$ by modifying the network topology and associated molecular constraints; non-optimal stoichiometries compound this through reduced cross-link densities, further variations in local network topologies and, in particular, the inclusion of epoxy-terminated branched structures.

\section{AC breakdown strength}

The data obtained from AC breakdown testing were analysed assuming a 2-parameter Weibull distribution and resulting Weibull plots are presented in Fig. 7. Derived values of the scale $(\alpha)$ and shape $(\beta)$ parameters along with the per cent change in the former quantity relative to the reference samples are listed in Table 3. In the case of the compensated systems, the inclusion of $1 \%, 4 \%, 10 \%$ and $30 \%$ of the epoxide groups from the GPOSS can be seen to result in improvements in the breakdown strength by some $16 \%, 22 \%, 17 \%$ and $12 \%$, respectively, compared to the reference epoxy. In the case of the uncompensated systems, only in the case of $1 \mathrm{wt} \%$ GPOSS was an improvement in performance seen (an increase of $7 \%$ in $\alpha$ ); all the other uncompensated systems showed either a statistically insignificant change or a reduction in breakdown strength. It has been suggested in several studies that the POSS molecule facilitates localized charge motion within resin systems [32, 44, 46, 51], which serves to suppress the accumulation of free charges in the bulk, resulting in a more homogeneous electric field throughout the system. Consequently, as the external electric field increases, the internal field is kept uniform by the
POSS through a process termed by Takala et al. [46] "temporary charge scavenging". This process would continue until the breakdown strength is globally exceeded and the system fails. Such an explanation is consistent with the increased breakdown strength values seen within the X EG\% GPOSS sample set, albeit that the breakdown strength of the 10 EG\% GPOSS and 30 EG\% GPOSS compensated systems are lower than that of 4 EG\% GPOSS, indicating that $\alpha$ does to vary monotonically with GPOSS loading level. Furthermore, the very different dependence of breakdown strength on GPOSS content seen in the uncompensated systems demonstrates that the observed behaviour is a consequence of synergistic factors related to both the presence of the GPOSS, changes in the network structure and the influence of retained functional groups.

Furthermore, it has previously been suggested $[44,45]$ that phase separation of POSS can occur in epoxy-based matrices, to form localized regions containing a high concentration of POSS. This additional level of inhomogeneity may provide a potential explanation for the reduction in breakdown strength seen at high GPOSS loading levels in both compensated and uncompensated systems.

\section{Dielectric spectroscopy}

The effect of the stoichiometry on the dielectric behaviour of the GPOSS modified systems is illustrated in Fig. 8. Generally, the real part of the relative complex permittivity, $\varepsilon^{\prime}$, increases with increasing GPOSS loading, as shown in Fig. 8a and b. This variation is in good agreement with behaviour previously reported, where Takala et al. [46] explained a similar increase in $\varepsilon^{\prime}$ in terms of factors other than the POSS loading, such as the size and dispersion of the POSS. Conversely, Huang et al. [34] and Heid et al. [44] suggested that the silica core of POSS results in an increase in the mobility of charge carriers and it is this that increases the real part of the relative permittivity. Finally, it is possible that the observed increase in $\varepsilon^{\prime}$ has the same origin as the reduction in $T_{g}$ seen on introducing GPOSS, namely that the presence of the GPOSS serves to facilitate increased local mobility of dipolar species in response to the applied field. Nevertheless, this increase in $\varepsilon^{\prime}$ combined the increase in breakdown strength described above may have important technological consequences. Taking 4 EG\% GPOSS as an example, this 

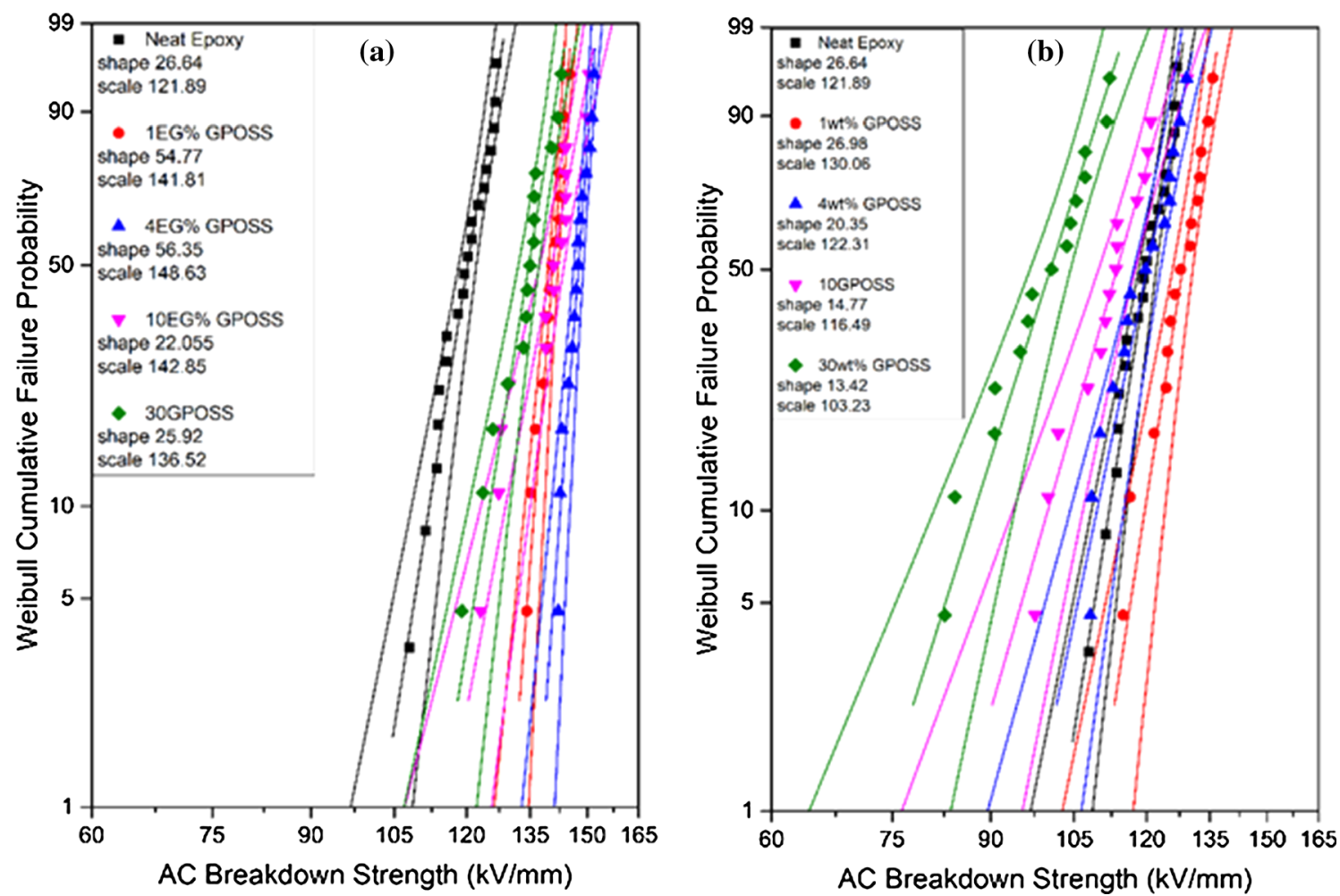

Figure 7 AC breakdown of reference and GPOSS modified systems with a compensated systems $\mathbf{b}$ uncompensated systems.

Table 3 AC breakdown strength data of the compensated and uncompensated GPOSS modified epoxy resin systems

\begin{tabular}{llllllll}
\hline Sample & \multicolumn{2}{l}{ Compensated systems } & & \multicolumn{2}{l}{ Uncompensated systems } \\
\cline { 2 - 3 } & Weibull $\alpha(\mathrm{kV} / \mathrm{mm})$ & Weibull $\beta$ & $\% \mathrm{BD}$ & & Weibull $\alpha(\mathrm{kV} / \mathrm{mm})$ & Weibull $\beta$ & $\% \mathrm{BD}$ \\
\hline Neat epoxy & 121.9 & 27 & 100 & & 121.9 & 27 & 100 \\
$1 \%$ & 141.8 & 55 & 116 & & 130.1 & 27 & 107 \\
$4 \%$ & 148.6 & 56 & 122 & & 122.3 & 20 & 100.3 \\
$10 \%$ & 142.9 & 22 & 117 & & 116.5 & 15 & 96 \\
$30 \%$ & 136.5 & 26 & 112 & 103.2 & 13 & 85 \\
\hline
\end{tabular}

system is characterized by a $10 \%$ increase in $\varepsilon^{\prime}$ and a $22 \%$ increase in the Weibull scale parameter, $\alpha$, compared with the base resin: this equates to a potential increase in the energy storage capacity of the system of around $50 \%$.

Figure $8 \mathrm{c}$ shows the dependence of the imaginary part of the relative permittivity, $\varepsilon^{\prime \prime}$, on the formulation for the X EG\% GPOSS sample set. The peak in the imaginary permittivity observed at frequencies above $10^{4} \mathrm{~Hz}$ is commonly attributed to the epoxy $\beta$ relaxation [37, 52-54] which, in amine-cured systems, originates from the motion of hydroxyl groups formed during cross-linking, together with a degree of cooperativity from the cross-links' surrounding structure [28]. From the FTIR data presented in Fig. 3a, it is evident that the inclusion of the GPOSS results in only marginal variations in the concentration of hydroxyl groups, which is largely independent of GPOSS concentration in these systems. As such, we suggest that the marked increase in the strength of the $\beta$-relaxation that can be seen in Fig. 8a should not be associated with an increase in the number of the associated diploes but, rather, with reduced local constraints, as a result of changes in the local molecular topology around the cross-links as a consequence of the inclusion of the GPOSS. That is, it is related to cooperativity with the cross-links' surrounding structure and, as such, mirrors the 

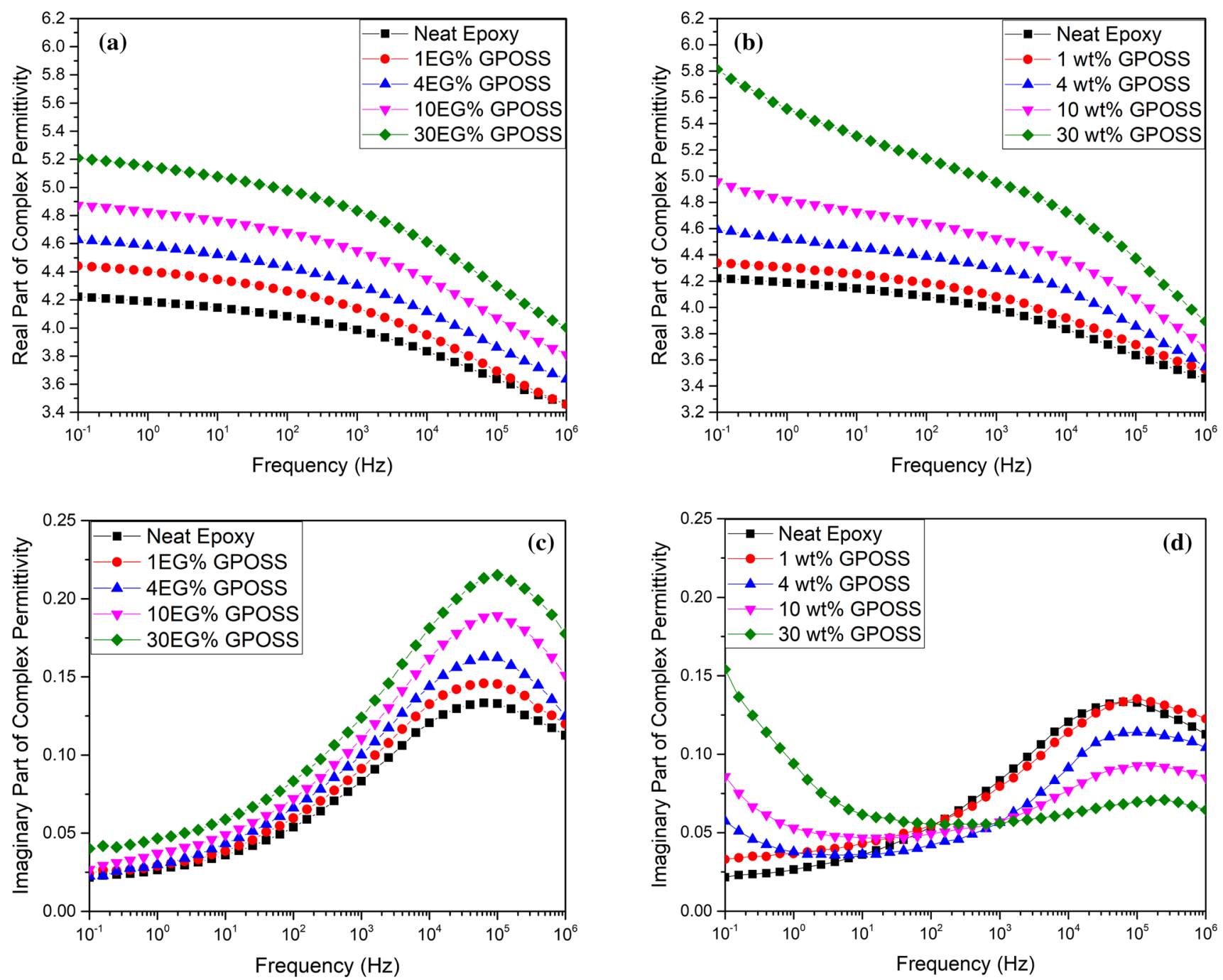

Figure 8 Real and imaginary part of the complex permittivity of reference and GPOSS modified systems a $\varepsilon^{\prime}$ for compensated systems b $\varepsilon^{\prime}$ for uncompensated systems $\mathbf{c} \varepsilon^{\prime \prime}$ for compensated systems $\mathbf{d} \varepsilon^{\prime \prime}$ for uncompensated systems.

explanation for the reduction in $T_{g}$ in the X EG\% GPOSS sample set proposed above.

Consider now the $\mathrm{Y}$ wt\% GPOSS systems where no compensation was made for the additional reactive epoxide groups present in the GPOSS. In considering the data presented in Fig. $8 \mathrm{~b}$ and d, two frequency ranges need to be discussed. First, the peak in $\varepsilon^{\prime \prime}$ at frequencies above $10^{4} \mathrm{~Hz}$ related to the $\beta$-relaxation and is therefore associated with the motion of dipolar species generated during curing. In these systems, it is evident that the strength of this dielectric feature decreases with increased GPOSS loading, despite the above inference drawn from the XEG\% GPOSS sample set that increasing the GPOSS content serves to increase molecular mobility in the system. We therefore suggest that, in the $\mathrm{Y}$ wt\% GPOSS systems, the dominant factor is rather a reduction in the concentration of the dipoles that contribute to this relaxation process, an assertion that aligns with the reduced hydroxyl absorbance seen in FTIR data presented in Fig. 3b. At frequencies below $10 \mathrm{~Hz}$, the data shown in Fig. 8d evince an increase in the imaginary part of the relative permittivity of the modified systems with decreasing permittivity, particularly for systems formulated using higher GPOSS loading levels. Heid et al. [32] reported similar low frequency behaviour, which they associated with phase separation of their POSS leading to interfacial polarization. While a similar explanation may apply here, two additional factors should also be considered. First, Heid et al. [32] employed triglycidylisobutyl POSS, which features only three 
pendant epoxide groups and which would therefore be more susceptible to phase separate. Second, although claimed workers claimed stoichiometric compensation, the absence of detail concerning this prevents objective evaluation of their approach. In contrast, the behaviour of the fully compensated systems presented in Fig. 8c reveals no evidence of comparable low frequency processes which, by implication, implies no tendency for GPOSS phase separation. Rather, this phenomenon appears to be a characteristic of non-optimal matrix stoichiometry and, presumably, modified charge transport dynamics. Indeed, in a separate study by David [55] on stoichiometric mixing on epoxy curing, it was observed that both either excess amine or excess epoxide groups produced samples with high ionic conduction levels providing evidence to the claim of modified charge transport dynamics.

\section{Conclusions}

The results presented above demonstrate that the behaviour of the two sets of systems considered here diverge increasingly as the loading level of GPOSS increases. FTIR spectroscopy shows that if appropriate stoichiometric compensation is made for the additional epoxide groups present on the GPOSS, then the presence of GPOSS has only a small effect on the cross-linking reactions that occur during curing. As such, we suggest that the reduction in $T_{g}$ that is observed in this sample set is caused by changes in network topology and associated molecular constraints as a result of the flexible vertex groups that link the GPOSS silica core to the reactive terminal epoxides. In contrast, if the GPOSS is added without consideration of the modified epoxide:amine ratio that results, then the presence of the consequent additional epoxide groups significantly modifies cross-linking, acts to promote etherification reactions and leads both to a reduction in the hydroxyl content of the system and the retention of unreacted epoxide chain ends. These changes manifest themselves as an additional influence on $T_{g}$, such that, in the case of the stoichiometrically uncompensated systems, $T_{g}$ decreases more rapidly with increasing GPOSS concentration than in the stoichiometrically compensated systems. If appropriate stoichiometric compensation is made, then the addition of GPOSS can result in a marked increase in material breakdown strength: all compensated systems exhibited improved performance, with the maximum breakdown strength being seen in the compensated system containing $4 \%$ of GPOSS. In the case of the uncompensated systems, only system containing $1 \mathrm{wt} \%$ GPOSS exhibited increased breakdown strength, indicating that while the presence of GPOSS is, in itself electrically beneficial, if its addition results in adverse changes to the matrix structure/chemistry, these latter factors swamp the benefits conferred by the GPOSS. In both system sets, the addition of GPOSS results in a general increase in the real part of the relative permittivity, albeit that a high GPOSS loading levels, this is more marked in the stoichiometrically uncompensated systems. In the compensated systems, the strength of the $\beta$-relaxation increases with GPOSS loading. Since this process is generally accepted to arise from the motion of hydroxyl groups and adjacent network segments formed during the reaction of epoxide and amine groups, the invariance in the strength of the FTIR hydroxyl peak within this sample set implies that the observed increase in the strength of the $\beta$-relaxation is not related to an increase in the number of the associated diploes but, rather, with changes in local constraints. This parallels our explanation for the reduction in $T_{g}$ in the $X$ EG\% GPOSS sample set. Conversely, in the uncompensated systems, where FTIR shows a reduction in hydroxyl concentration with increased GPOSS loading, it is this factor that is dominant in causing a reduction in the strength of this dielectric feature. Furthermore, these systems also evince increases in $\varepsilon^{\prime \prime}$ at frequencies below $10 \mathrm{~Hz}$, which appears to be a characteristic of non-optimal matrix stoichiometry and, presumably, modified charge transport dynamics. Such an interpretation aligns with the reduction in breakdown performance exhibited by uncompensated systems compared with their stoichiometrically compensated counterparts.

In summary, the two system sets considered here reveal markedly different forms of behaviour. While the inclusion of GPOSS can result in beneficial changes in electrical properties, these gains are easily lost if consequential changes in the matrix polymer are not appropriately counteracted. Nevertheless, if the system is appropriately optimized, materials with pronounced improvements in technologically important characteristics - such as breakdown strength and energy storage capacity - can be designed. 


\section{Declarations}

Conflict of interest The Author(s) declare(s) that there is no conflict of interest.

Open Access This article is licensed under a Creative Commons Attribution 4.0 International License, which permits use, sharing, adaptation, distribution and reproduction in any medium or format, as long as you give appropriate credit to the original author(s) and the source, provide a link to the Creative Commons licence, and indicate if changes were made. The images or other third party material in this article are included in the article's Creative Commons licence, unless indicated otherwise in a credit line to the material. If material is not included in the article's Creative Commons licence and your intended use is not permitted by statutory regulation or exceeds the permitted use, you will need to obtain permission directly from the copyright holder. To view a copy of this licence, visit http://creativecommons.org/licen ses/by/4.0/.

\section{References}

[1] Morsch S, Liu Y, Lyon SB, Gibbon SR (2016) Insights into epoxy network nanostructural heterogeneity using AFM-IR. ACS Appl Mater Interfaces 8(1):959-966. https://doi.org/10. 1021/acsami.5b10767

[2] Russell BK, Takeda S, Ward C, Hamerton I (2019) Examining the influence of carboxylic anhydride structures on the reaction kinetics and processing characteristics of an epoxy resin for wind turbine applications. React Funct Polym 144:104353. https://doi.org/10.1016/j.reactfunctpolym.2019. 104353

[3] Bandyopadhyay A, Valavala PK, Clancy TC, Wise KE, Odegard GM (2011) Molecular modeling of crosslinked epoxy polymers: the effect of crosslink density on thermomechanical properties. Polymer 52(11):2445-2452. https://d oi.org/10.1016/j.polymer.2011.03.052

[4] Harani H, Fellahi S, Bakar M (1999) Toughening of epoxy resin using hydroxyl-terminated polyesters. J Appl Polym Sci 71(1):29-38. https://doi.org/10.1002/(Sici)1097-4628(1 9990103)71:1\%3c29::Aid-App5\%3e3.3.Co;2-Z

[5] Tang B, Liu X, Zhao X, Zhang J (2014) Highly efficient in situ toughening of epoxy thermosets with reactive hyperbranched polyurethane. J Appl Polym Sci. 131 (16). h ttps://doi.org/10.1002/app.40614
[6] Gui D, Gao X, Hao J, Liu J (2014) Preparation and characterization of liquid crystalline polyurethane-imide modified epoxy resin composites. Polym Eng Sci 54(7):1704-1711. https://doi.org/10.1002/pen.23712

[7] Park J-J (2013) Effects of reactive diluents on the electrical insulation breakdown strength and mechanical properties in an epoxy system. Trans Electr Electron Mater 14(4):199-202. https://doi.org/10.4313/teem.2013.14.4.199

[8] Calventus Y, Montserrat S, Hutchinson JM (2001) Enthalpy relaxation of non-stoichiometric epoxy-amine resins. Polymer 42(16):7081-7093. https://doi.org/10.1016/s0032-3861 (01)00133-1

[9] Morgan RJ, Kong F-M, Walkup CM (1984) Structureproperty relations of polyethertriamine-cured bisphenol-Adiglycidyl ether epoxies. Polymer 25(3):375-386. https://doi. org/10.1016/0032-3861(84)90291-X

[10] Jordan C, Galy J, Pascault J-P (1992) Measurement of the extent of reaction of an epoxy-cycloaliphatic amine system and influence of the extent of reaction on its dynamic and static mechanical properties. J Appl Polym Sci 46(5):859-871. https://doi.org/10.1002/app.1992. 070460513

[11] Patil PN, Rath SK, Sharma SK, Sudarshan K, Maheshwari P, Patri M, Praveen S, Khandelwal P, Pujari PK (2013) Free volumes and structural relaxations in diglycidyl ether of bisphenol-A based epoxy-polyether amine networks. Soft Matter 9(13):3589-3599. https://doi.org/10.1039/c $3 \mathrm{sm} 27525 \mathrm{f}$

[12] Nguyen V, Vaughan A, Lewin P, Krivda A (2015) The effect of resin stoichiometry and nanoparticle addition on epoxy/ silica nanodielectrics. IEEE Trans Dielectr Electr Insul 22(2):895-905. https://doi.org/10.1109/tdei.2015.7076790

[13] Alhabill FN andritsch T, Vaughan AS (2016) The effect of resin/hardener stoichiometry on the electrical properties of silicon nitride/epoxy nanocomposites. 2016 IEEE International Conference on Dielectrics (ICD), Vols. 1-2:100-103. https://doi.org/10.1109/ICD.2016.7547553

[14] Saeedi IA, Vaughan AS andritsch T, Virtanen S (2016) The effect of curing conditions on the electrical properties of an epoxy resin. In: Electrical Insulation and Dielectric Phenomena (CEIDP), 2016 IEEE Conference on. IEEE, Norway, pp 461-464. https://doi.org/10.1109/CEIDP.2016. 7785649

[15] Dasgupta D, Srividhya M, Sarkar A, Dubey M, Wrobel D, Saxena A (2017) Rubber nanocomposites with polyhedral oligomeric silsesquioxanes (POSS) as the nanofiller. Woodh Pub S Compos S 75:231-247. https://doi.org/10.1016/B9780-08-100409-8.00007-3

[16] Mishra K, Pandey G, Singh RP (2017) Enhancing the mechanical properties of an epoxy resin using polyhedral 
oligomeric silsesquioxane (POSS) as nano-reinforcement. Polym Test 62:210-218. https://doi.org/10.1016/j.polymerte sting.2017.06.031

[17] Cabanelas JC, Antonelli C, Miguel VS, Serrano B, Baselga J (2016) Spectroscopic Analysis of Epoxy/Thermoplastic Blends. In: Parameswaranpillai J, Hameed N, Pionteck J, Woo EM (eds) Handbook of Epoxy Blends. Springer International Publishing, Cham. pp 1-30. https://doi.org/10.1007/ 978-3-319-18158-5 20-1

[18] Cholake S, Mada M, Raman R, Bai Y, Zhao X, Rizkalla S, Bandyopadhyay S (2014) Quantitative analysis of curing mechanisms of epoxy resin by mid- and near- Fourier transform infra red spectroscopy. Defence Sci J 64(3):314-321. https://doi.org/10.14429/dsj.64.7326

[19] Smith RE, Larsen FN, Long CL (1984) Epoxy resin cure. II. FTIR analysis. J Appl Polym Sci. 29 (12):3713-3726. h ttps://doi.org/10.1002/app.1984.070291207

[20] Finzel MC, Delong J, Hawley MC (1995) Effect of stoichiometry and diffusion on an epoxy-amine reaction-mechanism. J Polym Sci Pol Chem 33(4):673-689. https://doi.org/ 10.1002/pola.1995.080330409

[21] Pavia DL, Lampman GM, Kriz GS, Vyvyan JA (2008) Introduction to Spectroscopy. Cengage Learning. https://doi. org/10.1021/ed056pA323.2

[22] Lambert J, Shurvell H, Lightner D, Cooks R (1998) Organic Structural Spectroscopy Prentice Hall London, UK. doi.org/https://doi.org/10.1021/ed075p1218

[23] Bellamy LJ (1975) The Infra-red Spectra of Complex Molecules. Springer, London, Uk. https://doi.org/10.1007/9 78-94-011-6017-9

[24] Ollier-Dureault V, Gosse B (1998) Photooxidation of anhydride-cured epoxies: FTIR study of the modifications of the chemical structure. J Appl Polym Sci 70(6):1221-1237. h ttps://doi.org/10.1002/(sici)1097-4628(19981107)70:6\%3c1 221::Aid-app19\%3e3.0.Co;2-1

[25] Nyquist R (2001) Theory of Vibrational Spectroscopy. In: Nyquist RA (ed) Interpreting Infrared, Raman and Nuclear magnetic resonance spectra. Academic Press, San Diego, pp 1-24. https://doi.org/10.1016/b978-012523475-7/501650

[26] Ouellette RJ, Rawn JD (2018) Ethers and Epoxides. In: Ouellette RJ, Rawn JD (eds) Organic Chemistry. Academic Press, pp 507-536. https://doi.org/10.1016/b978-0-12-8128 38-1.50017-7

[27] Nikolic G, Zlatkovic S, Cakic M, Cakic S, Lacnjevac C, Rajic Z (2010) Fast Fourier transform IR characterization of epoxy GY systems crosslinked with aliphatic and cycloaliphatic EH polyamine adducts. Sensors (Basel) 10(1):684-696. https://doi.org/10.3390/s100100684
[28] Saeedi IA, Andritsch T, Vaughan AS (2019) On the dielectric behavior of amine and anhydride cured epoxy resins modified using multi-terminal epoxy functional network modifier. Polymers-Basel 11(8):1271. https://doi.org/10.339 0/polym11081271

[29] Vryonis O, Riarh S, Andritsch T, Vaughan AS (2020) Stoichiometry and molecular dynamics of anhydride-cured epoxy resin incorporating octa-glycidyl POSS co-monomer. Polymer. https://doi.org/10.1016/j.polymer.2020.123312

[30] Fraga F, Vazquez EC, Rodríguez-Núñez E, Martínez-Ageitos JM (2008) Curing kinetics of the epoxy system diglycidyl ether of bisphenol A/isophoronediamine by Fourier transform infrared spectroscopy. Polym Advan Technol. 19(11):1623-1628. https://doi.org/10.1002/pat.1178

[31] Rodosek M, Mihelcic M, Colovic M, Sest E, Sobak M, Jerman I, Surca AK (2020) Tailored crosslinking process and protective efficiency of epoxy coatings containing glycidylPOSS. Polymers-Basel 12 (3). https://doi.org/10.3390/ polym12030591

[32] Heid T, Fréchette M, David E (2015) Nanostructured epoxy/ POSS composites: enhanced materials for high voltage insulation applications. IEEE Trans Dielectr Electr Insul 22(3):1594-1604. https://doi.org/10.1109/tdei.2015.7116355

[33] Ramírez C, Rico M, Torres A, Barral L, López J, Montero B (2008) Epoxy/POSS organic-inorganic hybrids: ATR-FTIR and DSC studies. Eur Polymer J 44(10):3035-3045. https://d oi.org/10.1016/j.eurpolymj.2008.07.024

[34] Huang X, Li Y, Liu F, Jiang P, lizuka T, Tatsumi K, Tanaka T (2014) Electrical properties of epoxy/POSS composites with homogeneous nanostructure. IEEE Trans Dielectr Electr Insul 21(4):1516-1528. https://doi.org/10.1109/tdei.2014. 004314

[35] Ellis B (1993) Chemistry and Technology of Epoxy Resins. Springer, Hall, UK. https://doi.org/10.1007/978-94-011-293 2-9

[36] Bakar M, Duk R, Przybyłek M, Kostrzewa M (2008) Mechanical and thermal properties of epoxy resin modified with polyurethane. J Reinf Plast Compos 28(17):2107-2118. https://doi.org/10.1177/0731684408091703

[37] Menczel JD, Prime RB (2009) Thermal Analysis of Polymers. John Wiley \& Sons, USA. https://doi.org/10.1002/ 9780470423837

[38] Pissis P, Fragiadakis D (2007) Dielectric studies of segmental dynamics in epoxy nanocomposites. Journal of Macromolecular Science, Part B 46(1):119-136. https://doi. org/10.1080/00222340601044284

[39] Su C-H, Chiu Y-P, Teng C-C, Chiang C-L (2010) Preparation, characterization and thermal properties of organicinorganic composites involving epoxy and polyhedral 
oligomeric silsesquioxane (POSS). J Polym Res 17(5):673-681. https://doi.org/10.1007/s10965-009-9355-y

[40] Hao N, Böhning M, Goering H, Schönhals A (2007) Nanocomposites of polyhedral oligomeric phenethylsilsesquioxanes and poly(bisphenol A carbonate) as investigated by dielectric spectroscopy. Macromolecules 40(8):2955-2964. https://doi.org/10.1021/ma070036c

[41] Raftopoulos KN, Pielichowski K (2016) Segmental dynamics in hybrid polymer/POSS nanomaterials. Prog Polym Sci 52:136-187. https://doi.org/10.1016/j.progpolym sci.2015.01.003

[42] Lee A, Lichtenhan JD (1998) Viscoelastic responses of polyhedral oligosilsesquioxane reinforced epoxy systems. Macromolecules 31(15):4970-4974. https://doi.org/10.1021/ ma9800764

[43] Liu H, Zhang W, Zheng S (2005) Montmorillonite intercalated by ammonium of octaaminopropyl polyhedral oligomeric silsesquioxane and its nanocomposites with epoxy resin. Polymer 46(1):157-165. https://doi.org/10.1016/j.pol ymer.2004.10.078

[44] Heid T, Frechette M, David E (2016) Enhanced electrical and thermal performances of nanostructured epoxy/POSS composites. IEEE Trans Dielectr Electr Insul 23(3):1732-1742. https://doi.org/10.1109/tdei.2016.005531

[45] Florea NM, Lungu A, Badica P, Craciun L, Enculescu M, Ghita DG, Ionescu C, Zgirian RG, Iovu H (2015) Novel nanocomposites based on epoxy resin/epoxy-functionalized polydimethylsiloxane reinforced with POSS. Compos B Eng 75:226-234. https://doi.org/10.1016/j.compositesb.2015.01. 043

[46] Takala M, Karttunen M, Pelto J, Salovaara P, Munter T, Honkanen M, Auletta T, Kannus K (2008) Thermal, mechanical and dielectric properties of nanostructured epoxy-polyhedral oligomeric silsesquioxane composites. IEEE Trans Dielectr Electr Insul 15(5):1224-1235. https://d oi.org/10.1109/tdei.2008.4656229

[47] Matějka L, Strachota A, Pleštil J, Whelan P, Steinhart M, Šlouf M (2004) Epoxy networks reinforced with polyhedral oligomeric silsesquioxanes (POSS): structure and morphology. Macromolecules 37(25):9449-9456. https://doi.org/10. 1021/ma0484577
[48] Neville K, Lee H (1967) Handbook of Epoxy Resins. MacGraw-Hill, Michigan, USA. https://doi.org/10.1002/app. 1970.070140126

[49] Bacosca I, Hamciuc E, Bruma M, Ronova IA (2010) Study of aromatic polyimides containing cyano groups. High Perform Polym 22(6):703-714. https://doi.org/10.1177/ 0954008309350784

[50] Donth E (1982) The size of cooperatively rearranging regions at the glass transition. J Non-Cryst Solids 53(3):325-330. https://doi.org/10.1016/0022-3093(82)9008 9-8

[51] Horwath JC, Schweickart DL, Garcia G, Klosterman D, Galaska M, Schrand A, Walko LC (2006) Improved electrical properties of epoxy resin with nanometer-sized inorganic fillers. In: Conference record of the 2006 twentyseventh international power modulator symposium. IEEE, pp 189-191. https://doi.org/10.1109/MODSYM.2006. 365213

[52] Hassan MK, Tucker SJ, Abukmail A, Wiggins JS, Mauritz KA (2016) Polymer chain dynamics in epoxy based composites as investigated by broadband dielectric spectroscopy. Arab J Chem 9(2):305-315. https://doi.org/10.1016/j.arabjc. 2015.07.016

[53] Jilani W, Mzabi N, Fourati N, Zerrouki C, Gallot-Lavallée O, Zerrouki R, Guermazi H (2016) A comparative study of structural and dielectric properties of diglycidyl ether of bisphenol A (DGEBA) cured with aromatic or aliphatic hardeners. J Mater Sci 51(17):7874-7886. https://doi.org/10. 1007/s10853-016-0043-0

[54] Mikolajczak G, Cavaille JY, Johari GP (1987) Dynamic mechanical behaviour and its dependence on preparation method of structural epoxide resin. Polymer 28(12):2023-2031. https://doi.org/10.1016/0032-3861(87)9 0036-x

[55] Day DR (1986) Effects of stoichiometric mixing ratio on epoxy cure: a dielectric analysis. Polym Eng Sci 26(5):362-366. https://doi.org/10.1002/pen.760260507

Publisher's Note Springer Nature remains neutral with regard to jurisdictional claims in published maps and institutional affiliations. 